\title{
G6PD genetic variations in neonatal Hyperbilirubinemia in Indonesian Deutromalay population
}

Dewi A. Wisnumurti ${ }^{1,2}$, Yunia Sribudiani ${ }^{2,3^{*}}$ D, Robert M. Porsch ${ }^{4}$, Ani M. Maskoen ${ }^{2,3}$, Sri E. Rahayuningsih ${ }^{5}$, Eni K. Asni ${ }^{6}$, Frank Sleutels ${ }^{7}$, Wilfred F. J. van Ijcken ${ }^{7}$, Abdurachman Sukadi ${ }^{8}$ and Tri H. Achmad ${ }^{3}$

\begin{abstract}
Background: Neonatal jaundice is a common finding in newborns in Asia, including Indonesia. In some cases, the serum total bilirubin levels exceeds the 95th percentile for hours of life (neonatal hyperbilirubinemia). Severe neonatal hyperbilirubinemia $(\mathrm{NH})$ could lead to kernicterus and neonatal death. Glucose-6-Phosphage Dehydrogenase (G6PD) genetic variations and deficiency have been reported in several studies to be associated with NH. This study aimed to analyze the G6PD genetic variations and its activity in neonates with and without hyperbilirubinemia in the Deutromalay Indonesian population.
\end{abstract}

Methods: Deoxyribose Nucleic Acid (DNA) was isolated from peripheral blood of 116 and 115 healthy term neonates with and without hyperbilirubinemia. All infants underwent the following laboratory examinations: routine hematologic evaluation, Coombs test, G6PD activity measurement using the Randox kit method, and serum total bilirubin level. All exons of the G6PD gene were targeted for deep sequencing using MiSeq (Illumina). An association study of G6PD polymorphisms with $\mathrm{NH}$ was performed using PLINK.

Results: The prevalence of G6PD deficiency in neonates with and without hyperbilirubinemia in Indonesian Deutromalay population were 1.72\% (95\% Confidence Interval (Cl): 0.6-4.1\%) and 1.74\% (95\% Cl: 0.7-4.1\%), respectively. The most common G6PD polymorphisms, i.e. rs 1050757/c.* + 357A > G, rs2230037/c.1311C > T, and rs2071429/c.1365-13 T/IVS11, were identified. However, none of those polymorphisms and their haplotype were associated with $\mathrm{NH}(p>0.05$, Odds Ratio $(\mathrm{OR}) \sim 1.00)$. The prevalence of G6PD mutations in neonates with and without hyperbilirubinemia were 6.8\% (95\% Cl: $2.3-11.5 \%)$ and 6.9\% (95\% Cl: $2.3-11.6 \%)$, respectively. The most frequently identified G6PD mutation was the Viangchan variant (p.V291 M), which was followed by the Canton (p.R459L) and Vanua Lava (p.L128P) variants. Two novel mutations were identified both in case (p.V369A, p.I167F) and control (p.L474=, p.136T) groups.

Conclusion: The prevalence of G6PD deficiency is low in neonates with or without hyperbilirubinemia in Deutromalay Indonesian population. The majority of G6PD mutations identified among Indonesian Deutromalay population in this study are Viangchan, Canton and Vanua Lava variants.

Keywords: Deutromalay, G6PD deficiency, Genetics variation, Neonatal Hyperbilirubinemia

\footnotetext{
* Correspondence: y.sribudiani@unpad.ac.id; yungfb@gmail.com

${ }^{2}$ Research Center of Medical Genetics, Faculty of Medicine, Universitas

Padjadjaran, Bandung, Indonesia

${ }^{3}$ Department of Biomedical Sciences, Division of Biochemistry and Molecular

Biology, Faculty of Medicine, Universitas Padjadjaran, Bandung, Indonesia

Full list of author information is available at the end of the article
}

(c) The Author(s). 2019 Open Access This article is distributed under the terms of the Creative Commons Attribution 4.0 International License (http://creativecommons.org/licenses/by/4.0/), which permits unrestricted use, distribution, and reproduction in any medium, provided you give appropriate credit to the original author(s) and the source, provide a link to the Creative Commons license, and indicate if changes were made. The Creative Commons Public Domain Dedication waiver (http://creativecommons.org/publicdomain/zero/1.0/) applies to the data made available in this article, unless otherwise stated. 


\section{Background}

Glucose-6-phosphate-dehydrogenase (G6PD) is a "housekeeping" gene encoding the G6PD enzyme which catalyzes glucose-6-phoshpate conversion to 6phosphogluconolactone in the pentose monophosphate pathways in all cells $[1,2]$. This enzyme is also important for maintaining red blood cells (RBCs) and protecting them from damages or premature destruction caused by oxidative stress through the maintenance of Nicotinamide Adenine Dinucleotide (NADP) and Nicotinamide Adenine Dinucleotide Phosphate Hydrogen (NADPH) levels [1, 2]. Although G6PD deficiency affects all cells in the body, the most affected cells are RBCs because these cells have no alternative pathways to produce NADPH [1]. The G6PD gene, $18 \mathrm{k}$ base $(\mathrm{kb})$ long and is located on chromosome $\mathrm{Xq} 28$, consists of 13 exons and 12 introns. The complete coding sequence is 1548 base pair (bp) long and encodes 514 amino acids $[1,3,4]$. Mutations throughout the G6PD gene lead to a deficiency in protein functions. Based on their biochemical and physicochemical characteristics, over 400 variants of G6PD have been reported. However, based on the type of mutations, those protein variants resulted from only $\sim 140$ different mutations [3-5]. Glucose-6-phosphate-dehydrogenase deficiency is the most common pentose monophosphate pathway enzyme deficiency that has been reported to affect 400 million people globally with the highest incidence in African, Mediterranean, and South Asian populations $[3,6]$.

G6PD deficiency is inherited in an X-linked fashion, being fully expressed in hemizygous males and homozygous females. In most cases, G6PD deficiency is asymptomatic. However, in some cases, acute hemolysis could be induced by oxidative stress, such as in hypoxia, bacterial or viral infection, or exposure to certain foods (e.g., Fava beans), chemicals, or drugs (e.g., quinolones/ antimalarials) [7]. G6PD deficiency can also cause lifethreatening hemolytic anemia during childhood with severe neonatal hyperbilirubinemia $(\mathrm{NH})$ as the most fatal consequences of G6PD deficiency that can lead to chronic bilirubin encephalopathy (kernicterus) and spastic cerebral palsy [7].

G6PD deficiency and genetic variations (polymorphism and mutations) have been reported to be associated with hemoglobinuria or $\mathrm{NH}$ in several populations $[6,8]$. Neonatal hyperbilirubinemia is quite common in Indonesia; however, it is not yet known whether G6PD genetic variants (polymorphisms and mutations) and deficiency are the risk factors for $\mathrm{NH}$ in the Indonesian population. Here we present a complete mutational and polymorphism analysis of G6PD and its activity in newborns with and without hyperbilirubinemia in Indonesian Deutromalay population.

\section{Methods}

Subjects

The subjects were healthy term neonates with hyperbilirubinemia $(\mathrm{NH})$, defined as total serum bilirubin (TSB) above the 95th percentile for age in hours based on Bhutani's nomogram. Neonates with TSB below the 40th percentile for age in hours based on Bhutani's nomogram were included in this study as the control group. All neonates in both groups were single births. Neonates born to mothers with diabetes and those with neonatal sepsis, cephalohematoma, ABO or Rhesus blood group incompatibility with their mothers, or other congenital diseases which would affect the level of bilirubin in the serum were excluded. Two hundreds Seventy Six healthy term neonates from the Indonesian Deutromalay population were recruited consecutively from 5 hospitals in Sumatra and western part of Java islands. In total, only 116 and 115 neonates met the inclusion criteria for case and control groups, respectively, were included in this study. Written informed consent was obtained from parents, and the study was approved by the Ethics Committee of the Faculty of Medicine, Universitas Padjadjaran, Bandung, Indonesia. The characteristics of neonates and their mothers are presented in Table 1.

\section{Measurement of G6PD activity}

Red blood cell (RBC) G6PD activity assays was performed in 231 neonates using a G6PD assay kit from Randox Laboratory LTD (PD410, United Kingdom) in triplicate for each sample. All G6PD activity assays were performed within $24 \mathrm{~h}$ of sample collection. Results of G6PD measurement were calculated in mUnits $(\mathrm{U}) / 10^{9}$ erythrocytes. The G6PD enzyme activity was then converted into Units per $g$ Hemoglobin (U/g Hb). The median value of G6PD activity of male in control group $(13.10 \mathrm{U} / \mathrm{g} \mathrm{Hb})$ was used as the standard for $100 \%$ enzyme activity in this study. The results of G6PD activities were classified as deficiency when the enzyme activity was $<30 \%$ and was considered as intermediate and normal when the activity was $30-80 \%$ and $>80 \%$, respectively.

\section{DNA isolation}

Genomic DNA was isolated from $300 \mu \mathrm{l}$ of peripheral blood leukocytes using a DNA isolation kit (Roche Life Sciences) according to the manufacturer's protocol. The DNA concentration was measured using a NanoDrop $^{\mathrm{TM}} 2000$ (Thermo Fisher Scientific).

\section{Deep-targeted next-generation sequencing (NGS) and data analysis}

The G6PD gene was enriched with the TruSeq Custom Amplicon assay (Illumina, San Diego, USA) and oligos were designed using Design Studio (Illumina, San Diego, USA). Amplicons covered all exons and exon-intron 
Table 1 Characteristic of Neonates and Mothers in Case and Control Groups

\begin{tabular}{|c|c|c|c|c|c|}
\hline \multirow[t]{2}{*}{ Characteristic } & \multicolumn{2}{|l|}{ Cases } & \multicolumn{2}{|l|}{ Controls } & \multirow[t]{2}{*}{$p$-value* } \\
\hline & $(N=116)$ & $\%$ & $(N=115)$ & $\%$ & \\
\hline \multicolumn{6}{|l|}{ Neonates } \\
\hline Birth Weight (gram) & & & & & 0.772 \\
\hline Average (SD) & $3125(345.6)$ & - & $3138(371.2)$ & - & \\
\hline Range & $2500-4300$ & - & $2500-4250$ & - & \\
\hline Feeding & & & & & 0.483 \\
\hline Breast milk & 94 & 81.0 & 98 & 85.3 & \\
\hline Formula & 0 & 0 & 0 & 0 & \\
\hline Mix of both & 22 & 19.0 & 17 & 14.7 & \\
\hline Sibling with Jaundice & & & & & 0.319 \\
\hline Yes & 26 & 22.4 & 19 & 16.4 & \\
\hline No & 90 & 77.6 & 96 & 80.6 & \\
\hline ABO Blood Group & 18 & 15.5 & 9 & 7.75 & 0.065 \\
\hline \multicolumn{6}{|l|}{ Coombs Test Results } \\
\hline Negative & 116 & & 115 & & - \\
\hline Positive & 0 & & 0 & & \\
\hline \multicolumn{6}{|l|}{ Mothers } \\
\hline \multicolumn{6}{|l|}{ Age (Years) } \\
\hline Average (SD) & $30(6.1)$ & - & $30.9(5.8)$ & - & 0.208 \\
\hline \multicolumn{6}{|l|}{ Parity } \\
\hline 1 & 54 & 46.6 & 41 & 35.7 & 0.063 \\
\hline \multicolumn{6}{|l|}{ Delivery method } \\
\hline Cesarean delivery & 57 & 49.1 & 87 & 75.7 & $<0.001$ \\
\hline Normal & 53 & 45.7 & 28 & 24.3 & \\
\hline Vacuum & 3 & 2.6 & 0 & 0 & \\
\hline Forceps & 3 & 2.6 & 0 & 0 & \\
\hline Consanguinity & & & & & - \\
\hline No & 116 & 100 & 115 & 100 & \\
\hline
\end{tabular}

*) Chi-square. except Birth weight

boundaries with $10 \mathrm{bp}$ on each end. The amplicons were sequenced using paired-end sequencing of $2 \times 250 \mathrm{bps}$ on a MiSeq (Illumina, San Diego, CA, USA). Data processing was performed as described in the previous study [9]. Variants that were not present in the database of Single Nucleotide Polymorphism 138 (dbSNP138) or had minor allele frequencies (MAFs) $<0.01$ in the 1000 Genomes Project database were categorized as mutations (rare variants) and variants that were present in the dbSNP138 database with MAFs $\geq 0.01$ in the 1000 Genomes Project database were categorized as polymorphisms (common variants).

\section{Association analysis of identified polymorphisms}

Association analysis of polymorphisms with $\mathrm{NH}$ was performed using PLINK, an open-source whole-genome- association analysis tool set which can be used to perform a range of basic to large-scale association analyses of genotype/phenotype data [10]. Polymorphisms that were monomorphic had MAFs less than 0.05 or were missing in 95\% all subjects were excluded from the association test. The false discovery rate was used for multiple testing to correct $P$ values [11].

\section{Validation of G6PD mutations}

Mutations identified by targeted deep sequencing using Next-Generation Sequencing (NGS) method on MiSeq (Illumina, San Diego, CA, USA) were validated using polymerase chain reaction (PCR) and Sanger sequencing. Validation was only performed when DNA was still available. The primers used to amplify target exons of G6PD were designed using Primer3 V.0.4.0 software (http://bioinfo.ut.ee/primer3-0.4.0/) and the primers sequences were presented in Additional file 1: Table S1. Polymerase Chain Reaction (PCR) and Sanger sequencing to validate the mutations identified by MiSeq were performed as described in our previous study [9].

\section{In silico analysis}

The pathogenicity of identified G6PD mutations was predicted using Polymorphism Phenotyping V2 (PolyPhen-2) (http://genetics.bwh.harvard.edu/pph2/) and Mutation Taster (http://www.mutationtaster.org/) program.

\section{Results}

\section{Subjects characteristics}

Although the difference was not significant, there were more boys $(52.2-52.6 \%)$ than girls $(47.4-47.8 \%)$ in both case and control groups. The mean birth weight was $3125 \pm 345 \mathrm{~g}$ in the case group and $3138 \pm 371 \mathrm{~g}$ in the control group. The results of $\mathrm{ABO}$ and Rhesus blood grouping incompatibility between mothers and neonates were negative in all samples (Table 1). There was no significant difference in feeding methods, maternal age, or parity between case and control groups. The majority of mothers in both groups had Cesarean delivery (57-87\%) (Table 1). The histogram of total serum bilirubin (TSB) level distribution in case and control groups is presented in Fig. 1.

\section{The prevalence of G6PD deficiency}

The prevalence of G6PD deficiency in case $(2 / 116)$ and control (2/115) groups were $1.72 \%$ (95\% CI: $0.6-4.1 \%)$ and $1.74 \%$ (95\% CI: $0.7-4.1 \%)$, respectively.

\section{G6PD polymorphisms and association study}

Nine G6PD polymorphisms were identified in cases and controls but only three of them (rs1050757/c." + 357A > G, rs2230037/c.1311C > T, and rs2071429/c.1365-13 T/ IVS11) had MAFs $>0.05$ in this population. Therefore, 

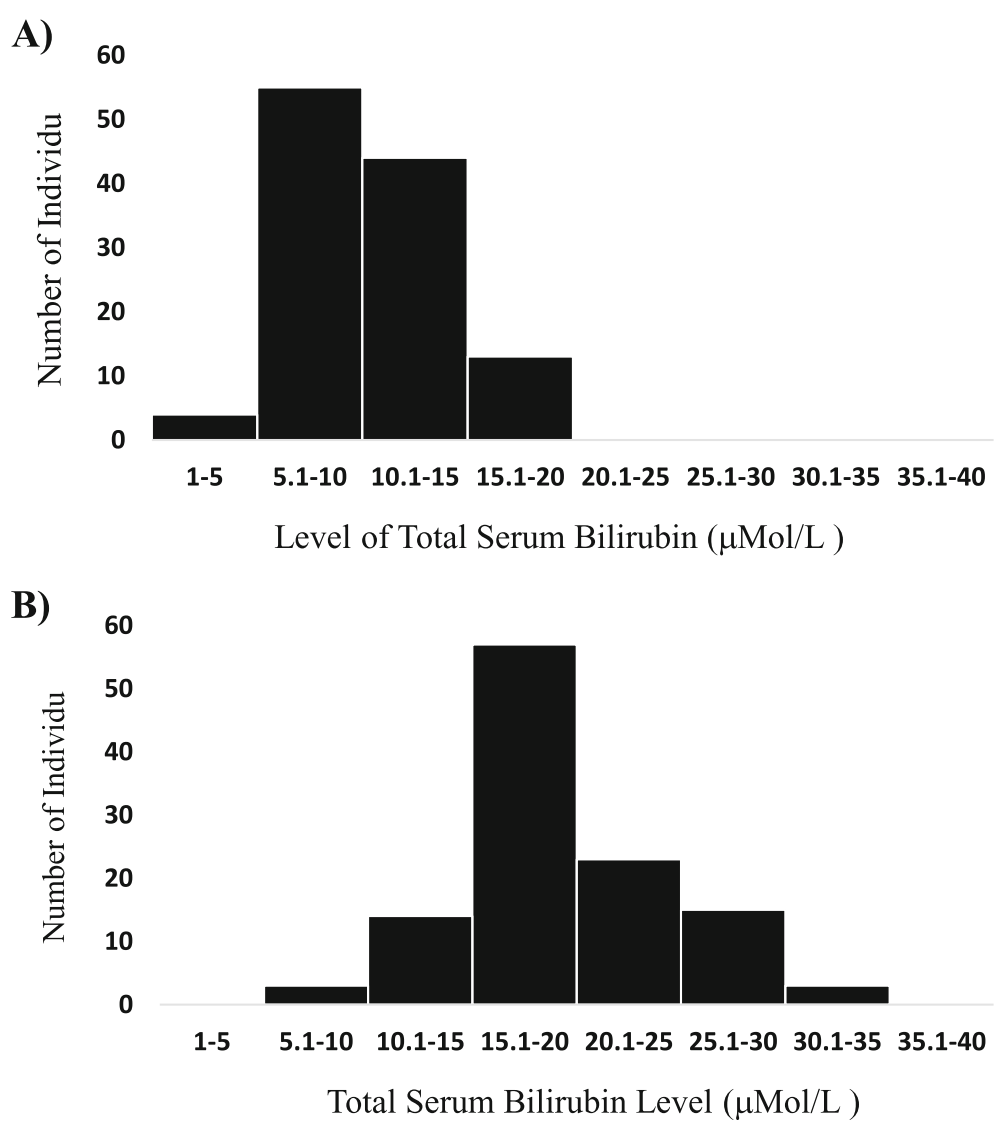

Fig. 1 Histogram of Total Serum Bilirubin (TSB) level ( $\mu$ Mol/L) distribution in: a) Neonates without hyperbilirubinemia (control group) and b) Neonates with hyperbilirubinemia (Cases group)

only those three polymorphisms and combinations of these variants (haplotypes) can be analyzed using PLINK. None of those polymorphisms and haplotypes were associated with $\mathrm{NH}$ in this population, as the $p$-value was $>0.05$ and the OR was $\sim 1.00$ (Table 2). In total, there were 4 G6PD-deficient subjects in case and control groups, but only 2 (50\%) were identified with a combination of these three polymorphisms (Table 3).

\section{G6PD mutations and in silico analysis}

The frequencies of mutations in the case and control groups were not significantly different. Eight G6PD mutations were identified in each group, hence the G6PD mutation frequencies in cases (8/116) and controls (8/ 115 ) were $6.8 \%$ (95\% CI:2.3-11.5\%) and 6.9\% (95\% CI:
2.3-11.6\%), respectively (Table 3 ). In total, from those neonates who carried G6PD mutations, nine different mutations identified in six and eight neonates from the case and control groups, respectively (Table 3). Among those mutations, two novel mutations were identified in both case and control groups. The two novel mutations identified in cases were all missense mutations (c.1106 $\mathrm{T}>\mathrm{C} / \mathrm{p}$. V369A and c.499A > T/p.I167F), whereas in controls, one of them was a silent mutation (c.1422G > A/ p.L474=) and the other was a missense mutation (c.107 $\mathrm{T}>\mathrm{C} / \mathrm{p} . \mathrm{I} 36 \mathrm{~T}$ ). The Viangchan variant (c.871G $>\mathrm{A} /$ p.V291 M) was the most frequently identified mutation in both cases and controls (three neonates in each group), followed by the Canton variant (c.1376G > T/ p.R459L) and Vanua Lava variant (c.383TA/p.L128P)

Table 2 Association of G6PD Polymorphisms with $\mathrm{NH}$

\begin{tabular}{|c|c|c|c|c|c|c|c|c|c|c|c|c|}
\hline No. & SNP & Location & AA Change & Coordinate (Hg19) & Ref & F_A & F_U & Alt & $P$ & OR & $95 \% \mathrm{Cl}$ & q-value \\
\hline 1 & rs1050757 & Intronic & - & $153,759,858$ & C & 0.3000 & 0.2692 & $\mathrm{~T}$ & 0.4626 & 1.163 & $0.66-2.06$ & 0.6168 \\
\hline 2 & rs2230037 & $3 U T R$ & - & $153,760,654$ & A & 0.2913 & 0.2735 & G & 0.6702 & 1.092 & $0.62-1.94$ & 0.7468 \\
\hline 3 & rs2071429 & Exon 11 & p.Y437= & $153,760,508$ & G & 0.2913 & 0.2778 & $A$ & 0.7468 & 1.069 & $0.60-1.89$ & 0.7468 \\
\hline
\end{tabular}

$A A$ Amino Acid, Alt Alternative, $C l$ Confidence of Interval, $F_{-} A$ Frequency Alt in Cases, $F_{-} U$ Frequency Alt in Controls, $\mathrm{Hg} 19$ Human genome version 19 , OR Odds Ratio, Ref Reference 


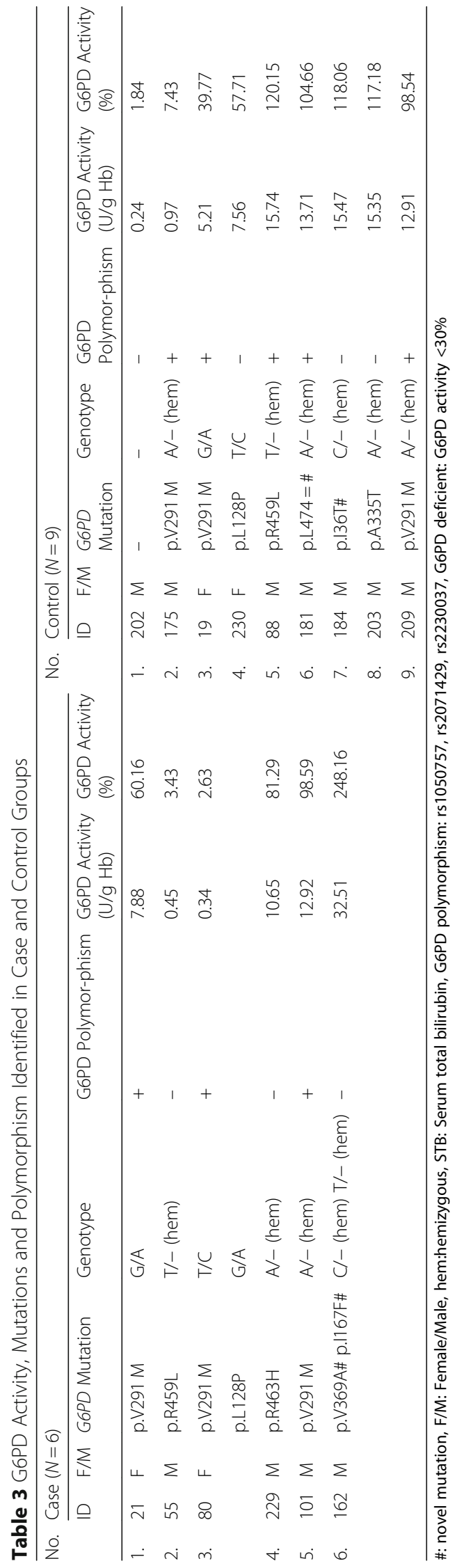


which were identified in one neonate in each group. The Kaiping variant (c.1388G > A/p.R463H) was identified only in one case, and the Chatham variant (c.1003G > A/ p.A335T) was identified only in one control (Table 3). The mutations identified in this population differ from those in previous studies in eastern Indonesian population, in which the predominant variant identified was the Vanua Lava variant [12, 13]. Among 4 G6PDdeficient neonates, two and one subjects in case and control groups, respectively, were identified as carriers of G6PD mutations. In the case group, one had the Canton Variant (p.R459L) and the other had a compound heterozygote with the Viangchan and Vanua Lava (p.L128P) variants (Table 3). In the control group, one subject was identified with the Viangchan variant, and the other did not have either G6PD mutation or polymorphism (Table 3). Hence, in this population, 75\% (3/ 4) of G6PD-deficient neonates were carrying G6PD mutations. To predict the pathogenicity of identified mutations, in silico analysis using Polypen-2 and Mutation Taster $^{\bullet}$ was performed. Most of the identified mutations, including the novel ones, were predicted to be diseasecausing or possibly damage-causing variants (Additional file 1: Table S2). Functional studies on novel mutations are required to validate the results of in silico analysis.

\section{Validation of G6PD mutations}

Among the nine different mutations identified in a total of 14 neonates (six in case group and eight control group), only five different mutations (56\%) in seven neonates $(50 \%)$ were validated by PCR and Sanger sequencing. Those were the Vanua Lava, Chatham, Canton, Viangchan, and Kaiping variants (Additional file 1: Figure S1-S2). Since the DNA samples of the other seven neonates were no longer available or the quality was significantly decreased, the mutations could not be validated by using Sanger sequencing.

\section{Discussion}

The pathophysiology of $\mathrm{NH}$ is complex and multifactorial. Studies that have been conducted so far have focused on the prevalence of $\mathrm{NH}$ in G6PD-deficient neonates and shown that G6PD deficiency is one of the risk factors for $\mathrm{NH}$ in several populations or, at least, that G6PD-deficient neonates have significantly higher bilirubin levels than controls $[8,14]$. To date, more than 150 $G 6 P D$ variants have been identified as causal or risk factors in G6PD deficiency. Very limited studies have been performed to analyze G6PD variants (mutations and polymorphisms) in $\mathrm{NH}$ and the association of those variants with $\mathrm{NH}$. One study has suggested that G6PDdeficient neonates carrying the c.563C $>\mathrm{T} G 6 P D$ variant developed jaundice earlier than infants without G6PD deficiency [15].
The results of this study show that the prevalence of G6PD deficiency in neonates with hyperbilirubinemia $(\mathrm{NH})$ in this population (1.72\%). This number is lower than the prevalence of G6PD deficiency in Malaysia (29.7\%), Thailand (22.9\%), Egypt (30.2-42\%), Pakistan (17.3\%) and India (2.5\%) [1, 15-17]. The prevalence of G6PD deficiency in $\mathrm{NH}$ in this population was also lower than in the population infected by Malaria in eastern Indonesian population (Flores [4.4\%] and Sumbawa [3.1-6.7\%]) [12, 13]. Furthermore, the prevalence of G6PD deficiency in case group (1.72\%) was similar to that in control group (1.74\%) (Table 3). This shows that G6PD deficiency is not a major risk factor in the etiology of $\mathrm{NH}$ in this population.

Variant analysis using targeted deep sequencing allows us to accurately genotype all mutations and polymorphisms in the exonic regions, their flanking sites, and small parts of the upstream ( $3^{\prime}$-UTR) and downstream (5'-UTR) regions of the gene. Three polymorphisms (rs1050757, rs2230037, and rs2071429) with MAF $>0.05 \%$ were identified in cases and controls. Among those polymorphisms, only one was located in the coding region: rs2071429 (p.Y437=). This variant is a silent polymorphism with frequencies of $29 \%$ $(0.2913)$ in $\mathrm{NH}$ and $28 \%(0.2778)$ in controls (Table 2). Association analysis using PLINK showed that neither of these polymorphisms nor their combination (haplotype) were associated with $\mathrm{NH}$. This study has a limitation in the form of significantly different cesarean-section rates in case and control groups (Table 1). This could introduce bias to the results of this study as the cesarean-section itself has been reported in the previous studies to be associated with hyperbilirubinemia $[18,19]$.

In total, there were 6 and 8 neonates from the case and control groups, respectively, were identified as carriers of G6PD mutations. However, despite of carrying G6PD mutations with or without polymorphism, only 2 neonates from each group suffer from G6PD deficiency. Three of those four G6PD-deficient neonates (75\%) carry G6PD mutations with or without polymorphism and one of them does not have any G6PD coding mutation or polymorphism. This number is similar to those identified in Egyptian and Chinese population, where 62 and $78 \%$ of G6PD-deficient neonates, respectively, are identified as carriers of G6PD mutations, but lower than that in Singaporean (90\%) and Pakistani population (94\%) $[14,17,20,21]$. Previous studies have shown that some variants or a haplotype in the non-coding region of G6PD (+357A > G/c.1365-13 T > C/c.1311C > T) were associated with the lower enzyme activity in individual without G6PD mutation in the coding region [21]. As in the deep-targeted sequencing method only small part of UTRs and intronic regions are included in the analysis, there is a possibility that we missed in identifying noncoding mutation in one of G6PD-deficient neonates. 
G6PD deficiency is inherited in X-linked recessive pattern, hence this condition mostly affects male neonates. It is interesting to note that in this study, one of affected neonates is female. Her enzyme activity was only $2.63 \%$ of normal G6PD activity. This female neonate (ID-80) have compound heterozygous of Vianchan and Canton variants with polymorphism. This showing that gene dosage affects the severity of the enzyme deficiency. However, predicting the effect of a G6PD mutation in females is more complicated than in their male counterparts. Although the females have two X chromosomes, one $\mathrm{X}$ chromosome is randomly inactivated during embryogenesis. The total gene expression will depend on the ratio of the $\mathrm{X}$-inactivated wild-type allele to the mutant allele. The remaining G6PD mutations were identified in male neonates, and most of them did not suffer from G6PD deficiency (Table 3).

Of all G6PD mutations identified in this study, the most common is the Viangchan variant (p.V291 M), followed by the Canton (p.R459L) and Vanua Lava (p.L128P) variants, which are located in exons 9, 12, and 5 , respectively. The predominant mutational type identified in this study was different from those in other ethnic groups in Indonesia. A study in Sumba, eastern Indonesia, has shown that the predominant $G 6 P D$ mutation identified in this ethnic group is Vanua Lava [12]. Indonesia is an archipelago country, with thousands of islands and more than 100 ethnic groups. It is not surprising that the predominant mutational type is different in each region in Indonesia. The ancestors of the Deutromalay, who inhabits the western part of Indonesia, are believed to have come from northern China who were migrated to Southeast Asia. Therefore, the variants identified in this ethnic group are similar to those in China, Thailand, and other Southeast Asian countries.

\section{Conclusion}

The prevalence of G6PD deficiency is low in neonates with or without hyperbilirubinemia in Deutromalay Indonesian population. The G6PD mutations identified in this population are mostly similar to those identified in other South East Asian population.

\section{Supplementary information}

Supplementary information accompanies this paper at https://doi.org/10. 1186/s12887-019-1882-z

Additional file 1: Table S1. Primers for Exons of G6PD, Table S2. in silico Analysis of G6PD Mutations Identified in Cases and Controls, Figure S1. A) Hemizygous Canton variant c.1376G > T/p.R459L was identified in one case (ID-55) and in one control (ID-88). B) Hemizygous Kaiping variant c.1388G > A/p.R463H was identified in one case (Male, ID-229). F: Female, M: Male, WT: Wild-type, Figure S2. A) Heterozygous Vanua Lava variant c.383 T > C/p.L128P were identified one case (Female, ID-80) and one control (Female, ID-230). B) Hemizygous Chatham variant c.1003GT > A/p.A335T was identified one case (male, ID- 203). C) Viangchan variant was identified in three cases and three controls. F: Female, M: Male, WT: Wild-type.

\section{Abbreviations}

bp: base pairs; Cl: Confidence interval; DNA: Deoxyribose nucleic acid; G6PD: Glucose-6-Phosphage Dehydrogenase; Hb: Hemogblobin; Kb: kilobase pairs; MAF: Minor allele frequency; NAD: Nicotinamide adenine dinucleotide; NADPH: Nicotinamide adenine dinucleotide phosphate hydrogen; NGS: NextGeneration Sequencing; OR: Odds ratio; PCR: Polymerase chain reaction;

Polyphen-2: Polymorphism phenotyping v2; RBC: Red blood cells; SNP: Single nucleotide polymorphism; TSB: Total serum bilirubin; U: Unit

\section{Acknowledgements}

Authors would like to thank the parents who voluntary enrolled their neonates in this study. Authors would also like to extend their gratitude to Tetty Yuniati, MD., PhD from Dr. Hasan Sadikin General Hospital, Meiharty Zulkifli, MD from RSUD Pasar Rebo, and Setyadewi Lusyati, PhD from Harapan Kita Women and Children Hospital for their support in collecting blood samples and patients data for this study.

\section{Authors' contributions}

DAW, SER, AS and THA participated in study design, DAW and YS involved in the interpretation of targeted deep sequencing results and performed validation of MiSeq data by PCR and Sanger Sequencing. AMM and EKA performed DNA isolation. RMP performed the association study using PLINK. FS and WFJ van ljcken performed targeted deep sequencing using MiSeq. DAW involved in samples collection. All authors involved in data analysis. DAW, YS, AS and THA participated in drafting and writing the manuscript. All authors read and approved the final manuscript.

\section{Funding}

This study was financially supported by internal research grant from Universitas Padjadjaran (to THA and AMM) and Universitas Riau (to DAW). The above research grants were contributed in the process of sample and data collection, experiments, data interpretation and analysis as well as article-processing charge.

Availability of data and materials Not applicable.

Ethics approval and consent to participate

The Institutional Review Board of Faculty of Medicine, Universitas Padjadjaran, has approved the protocol for this study. Written informed consents from parents of neonates enrolled in this study were obtained.

Consent for publication

Not applicable.

\section{Competing interests}

The authors declare that they have no competing interests.

\section{Author details}

1Departement of Pediatric, Neonatology Subdivision, Arifin Achmad General Hospital, Universitas Riau, Pekanbaru, Indonesia. ${ }^{2}$ Research Center of Medical Genetics, Faculty of Medicine, Universitas Padjadjaran, Bandung, Indonesia. ${ }^{3}$ Department of Biomedical Sciences, Division of Biochemistry and Molecular Biology, Faculty of Medicine, Universitas Padjadjaran, Bandung, Indonesia. ${ }^{4}$ Department of Psychiatry, Li Ka Shing Faculty of Medicine, The University of Hong Kong, Hong kong SAR, China. ${ }^{5}$ Departement of Pediatric, Cardiology Subdivision, Dr. Hasan Sadikin Hospital, Faculty of Medicine, Universitas Padjadjaran, Bandung, Indonesia. ${ }^{6}$ Department of Biochemistry, Faculty of Medicine, Universitas Riau, Pekanbaru, Indonesia. ' $E$ Erasmus Center for Biomics, Erasmus MC, Rotterdam, The Netherlands. ${ }^{8}$ Departement of Pediatric, Neonatology Subdivision, Dr. Hasan Sadikin Hospital, Faculty of Medicine, Universitas Padjadjaran, Bandung, Indonesia. 
Received: 13 January 2019 Accepted: 10 December 2019

Published online: 20 December 2019

\section{References}

1. Sinha R, Sachendra B, Sabid Syed V, Nair L, John BM. To study the prevalence of glucose 6 phosphate dehydrogenase (G6PD) deficiency in neonates with neonatal Hyperbilirubinemia and to compare the course of the neonatal jaundice in deficient versus non deficient neonates. J Clin Neonatal. 2017:6(2):71-4.

2. WHO Working Group of G6PD Deficiency. Glucose-6-phosphate dehydrogenase deficiency. Bull World Health Organ. 1989;67(6):501-611.

3. Gómez-Manzo S, Marcial-Quino J, Vanoye-Carlo A, Serrano-Posada H, Ortega-Cuellar D, González-Valdez A, Castillo-Rodríguez RA, HernándezOchoa B, Sierra-Palacios E, Rodríguez-Bustamante E, Arreguin-Espinosa E. Glucose-6-phosphate dehydrogenase. Update and Analysis of New Mutations Around the World. Int J Mol Sci. 2016;17(12):2069.

4. Beutler $\mathrm{E}$. The molecular biology of G6PD variants and other red cell enzyme defects. Annu Rev Med. 1992;43:47-59.

5. Ho H, Cheng M, Chiu DT. Glucose-6-phosphate dehydrogenase - from oxidative stress to cellular functions and degenerative diseases. Redox Rep. 2007;12(3):109-18.

6. Hue NT, Charlieu JP, Chau TTH, Day N, Farrar JJ, Hien TT, Dunstan SJ. Glucose6-phosphate dehydrogenase (G6PD) mutations and Haemoglobinuria syndrome in the Vietnamese population. Malar J. 2009;8(1):1-8.

7. Beutler E. ASH 50th anniversary review Glucose-6-phosphate dehydrogenase deficiency : a historical perspective early history. Blood. 2018;111(1):16-25.

8. Weng YH, Chiu YW, Cheng SW, Yang CY. Risk assessment of gene variants for neonatal Hyperbilirubinemia in Taiwan. BMC Pediatr. 2016;16(1):1-5.

9. Wisnumurti DA, Sribudiani Y, Porsch RM, Maskoen AM, Abdulhamied LI, Rahayuningsih SE, Asni EK, Sleutels F, Kockx CEM, Van ljcken WFJ, Sukadi A Achmad TA. UGT1A1 genetic variations and a haplotype associated with neonatal Hyperbilirubinemia in Indonesian population. Biomed Res Int. 2018. https://doi.org/10.1155/2018/9425843.

10. Purcell S, Neale B, Todd-Brown K, ThomasL FMAR, Bender D, Maller J, Sklar P, de Bakker I, Daly MJ, Sham C. PLINK: a tool set for whole-genome association and population-based linkage analyses. Am J Hum Genet. 2007; 81(3):559-75.

11. Benjamini $Y$, Hochberg $Y$. Controlling the false discovery rate: a practical and powerful approach to multiple testing. J R Stat Soc Ser B Methodol. 1995;57(1):289-300.

12. Satyagraha AW, Sadhewa A, Baramuli V, Elvira R, Ridenour C, Elyazar I, Noviyanti R, Coutrier FN. G6PD deficiency at Sumba in eastern Indonesia is prevalent, diverse and severe : implications for Primaquine therapy against relapsing Vivax malaria. PLoS Negl Trop Dis. 2015;9(3): e0003602.

13. Matsuoka H, Arai M, Yoshida S, Tantular IS, Pusarawati S, Kerong H, Kawamoto F. Five different Glucose-6-Phophate dehydrogenase (G6PD) variants found among 11 G6PD-deficient persons in Flores Island, Indonesia. J Hum Genet. 2003:48:541-4.

14. Huang MJ, Yang YC, Yang SS, Lin MS, Chen ES, Huang CS. Coinheritance of variant UDP-Glucuronosyl Transferase $1 \mathrm{~A} 1$ gene and Glucose-6-phosphate dehydrogenase deficiency in adults with Hyperbilirubinemia. Pharmacogenetics. 2002;12(8):663-6.

15. Moiz B, Nasir A, Khan SA, Kherani SA, Qadir M. Neonatal Hyperbilirubinemia in Infants with G6PD c. 563C > T Variant. BMC Pediatr. 2012;12(1):1.

16. Ainoon O, Boo NY, Yu YH, Cheong SK, Hamidah NH, Lim JH. Complete molecular characterisation of Glucose-6-phosphate dehydrogenase (G6PD) deficiency in a Group of Malaysian Chinese. Malaysian J Patho. 2004;26(2):89-98.

17. Ezz El-Deen ZM, Hussin NF, Abdel Hamid TA, Abdel Migeed OR, Samy RM. G6PD deficiency and G6PD (Mediterranean and silent) polymorphisms in Egyptian infants with neonatal Hyperbilirubinemia. Lab Med. 2013;44(3): 228-34.

18. Norman M, Aberg K, Holmsten K, Weibel V, Ekeus C. Predicting nonhemolytic neonatal Hyperbilirubinemia. Pediatr. 2015;136(6):1087-94

19. Chen YJ, Chen WC, Chen CM. Risk factors for Hyperbilirubinemia in breastfed term neonates. Eur J Pediatr. 2012;171:167-71.

20. Hamada M, Shirakawa T, Poh-San L, Nishiyama K, Uga S, Matsuo M. Two new variants of G6PD deficiencies in Singapore. Nepal Med Coll J. 2010; 12(3):137-41.
21. Sirdah MM, Shubair ME, Al-kahlout MS, Prchal JT, Reading NS. Possible Association of $3^{\prime}$ UTR +357A>G, IVS1-nt93 T> C, c . 1311 C $>$ T Polymorphism with G6PD Deficiency. Hematology. 2017;22(6):370-4.

\section{Publisher's Note}

Springer Nature remains neutral with regard to jurisdictional claims in published maps and institutional affiliations.
Ready to submit your research? Choose BMC and benefit from:

- fast, convenient online submission

- thorough peer review by experienced researchers in your field

- rapid publication on acceptance

- support for research data, including large and complex data types

- gold Open Access which fosters wider collaboration and increased citations

- maximum visibility for your research: over $100 \mathrm{M}$ website views per year

At $\mathrm{BMC}$, research is always in progress.

Learn more biomedcentral.com/submissions 